\title{
Assessment of Relationship Between Insulin-Like Growth Factor- 1 Levels And Mp3 Radiographs in Determining Skeletal Maturity
}

\section{Sunil Muddaiah ${ }^{1}$, Sajai BharathV.U. ${ }^{2}$, Goutham B. ${ }^{3}$, Suhailuddin ${ }^{4}$, Vikram Susil ${ }^{5}$, Namitha Nanu ${ }^{6}$}

1. Dr Sunil Muddaiah M.D.S, Dean, Coorg Institute of Dental Sciences, Virajpet

2. Dr Sajai Bharath V.U M.D.S, Reader, KMCT Dental College, Calicut

3. Dr Goutham B M.D.S, Professor \& Head, Coorg Institute of Dental Sciences, Virajpet

4. Dr Suhailuddin M.D.S, Reader, Coorg Institute of Dental Sciences, Virajpet

5. Dr Vikram Susil M.D.S, Sr Lecturer, Coorg Institute of Dental Sciences, Virajpet

6. Dr Namitha Nanu M.D.S, Sr Lecturer, Coorg Institute of Dental Sciences, Virajpet

Corresponding author:

Dr. Sunil Muddaiah

Department of Orthodontics,

Coorg Institute of Dental Sciences,

Maggula P.O.,

Virajpet 571218,

Karnataka, India.

Phone number: 09448113013

E-mail address: sunil@cids.edu

\section{ABSTRACT}

\section{Context:}

The clinical importance of evaluating skeletal maturation has long been recognized by the health professions. Skeletal maturation is an integral part of individual patterns of growth and development.

With many orthodontic patients, pubertal growth needs to be factored into the diagnostic equation.

Accurate prediction of the timing of the pubertal growth spurt and the amount of remaining growth affects the treatment decisions in orthodontics, orthognathic surgery and dental implantology.

IGF-1 mirrors growth hormone levels. Thus, IGF-I might be a good indicator of residual mandibular growth.

\section{Aims:}

1. To establish a relationship between IGF-1 levels evaluated from blood samples and MP3 stages of skeletal maturity.

2. To investigate the relationship between the IGF-1 and the skeletal age.

\section{Methods and Material:}

The sample size consisted of 40 subjects between the age group of $5-25$ including both the sexes. The periapical radiographs for MP3 and blood sample for IGF-1 was collected. Sample was sent to the lab to determine IGF-1 values. 


\section{Statistical analysis used:}

Descriptives, ONE way ANOVA, POST HOC test, Spearman coefficient.

\section{Results:}

Results showed that IGF-1 levels at the peak pubertal growth were statistically higher than the start of pubertal growth, acceleration, deceleration, maturation of growth spurt and on completion of growth. There was statistically significant positive correlation between IGF-1 and MP3 stages.

\section{Conclusions:}

From the present study it can be concluded that IGF-1 can be successfully used as a skeletal maturity indicator.

\section{Key-words: IGF-1, MP3, GH}

Key Messages: The results of this study shows that mean IGF-I levels at pubertal and post pubertal stages were significantly higher than at the other stages. From the present study it can be concluded that IGF-1 can be successfully used as a skeletal

\section{Introduction}

Health professions have recognized the clinical importance of evaluating skeletal maturation which is an integral part of individual patterns of growth and development. Skeletal maturation is an integral part of individual patterns of growth and development. ${ }^{1}$ A critical variable in orthodontic treatment is the growth factor. Treatment plan can change from orthognathic surgery to extraction to non-extraction, based on the growth factor ${ }^{2}$. IGF-I plays an important role in systemic and local regulation of both prenatal and postnatal longitudinal bone growth. ${ }^{3}$ IGF-1 mirrors growth hormone levels. Thus, IGF-I might be a good indicator of residual mandibular growth ${ }^{4}$.

\section{AIMS}

1. To establish a relationship between IGF-1 levels evaluated from blood samples and MP3 stages of skeletal maturity.

2. To investigate the relationship between the IGF1 and the skeletal age.

\section{Subjects and Methods:}

The sample size consisted of 40 subjects. The subjects were selected from patients reporting to Department Of Orthodontics and Dentofacial Orthopaedics, Coorg institute of dental sciences, Virajpet. The subjects were those who were seeking orthodontic treatment, patients undergoing active orthodontic treatment or those who visit for post orthodontic follow up.

\section{Inclusion criteria}

1. Age group: 5-25 years.

2. Both sexes

Exclusion criteria included patients suffering from

1. Systemic illness.

2. Bleeding disorders.

3. Growth abnormalities and

4. Facial asymmetry.

Random sampling technique was employed.

\section{Procedure:}

The study sample included patients who reported for a minimum period of 6 months to the department of orthodontics. A thorough history was taken before selecting the subjects regarding their age, pubertal status and history of bleeding disorders. A standard dental radiograph (Kodak E-speed film $32 \mathrm{mmX} 41 \mathrm{~mm}$ ) of the MP3 (middle phalanx of the middle finger) will be taken. The periapical radiographs of the middle phalanx of the middle finger was examined and staged according to stages described by Kansal and Rajgopal.

Blood sample was collected for IGF-1. Serum was centrifuged and separated from the blood 


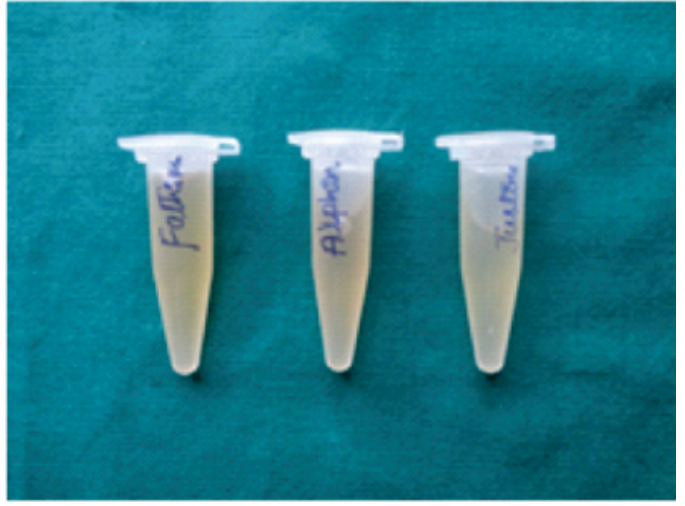

FIG. 1 - SERUM VIALS

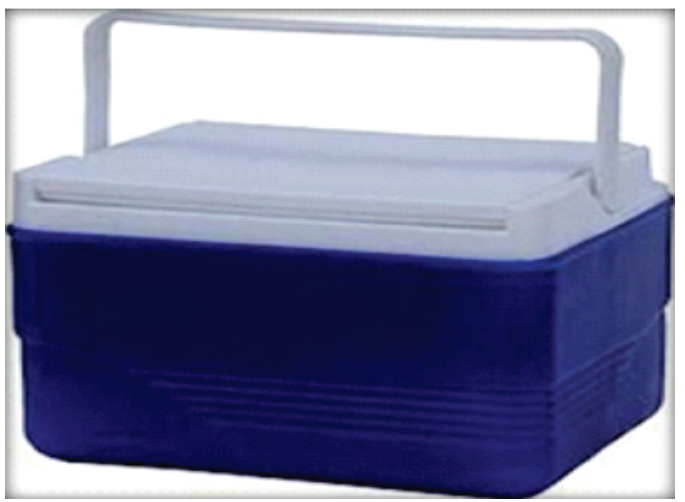

FIG. 2 - ICE BOX

samples and was transported in serum vials (fig.1) on the same day of collection in an ice box (fig.2) to the lab for enzyme immunoassay. The patients and parents were requested to sign consent forms.

The MP3 staging were originally described by Hagg and Taranger. In the present study MP3 radiographs were staged by using the 6 stages described by kansal and Rajgopal Based on the staging the first stage was considered the start of pubertal growth. The second stage is an acceleration of pubertal growth spurt. The 3rd stage is when there is a maximum point of pubertal growth spurt. The 4th stage is a deceleration of the pubertal growth spurt. In the fifth stage there is a maturation in the pubertal growth spurt. The sixth stage shows an end in pubertal growth spurt.

\section{Statistical methods applied:}

Descriptives, one way ANOVA and Post-Hoc tests using SPSS for windows software.

\section{Results:}

\section{Table I}

Table I shows the mean value of IGF-1 for each MP3 stages.

\begin{tabular}{|l|l|l|l|l|l|l|l|}
\hline \multicolumn{7}{|c|}{ ONEWAY ANOVA VALUE DESCRIPTIVES } \\
\hline & & & & \multicolumn{9}{|c|}{$\begin{array}{l}\text { Confidence } \\
\text { Interval for Mean }\end{array}$} & & \\
\hline & N & Mean & $\begin{array}{c}\text { Std. } \\
\text { Deviation }\end{array}$ & $\begin{array}{l}\text { Lower } \\
\text { Bound }\end{array}$ & $\begin{array}{c}\text { Upper } \\
\text { Bound }\end{array}$ & $\begin{array}{c}\text { Mini } \\
\text { mum }\end{array}$ & $\begin{array}{c}\text { Maxi } \\
\text { mum }\end{array}$ \\
\hline F & 7 & 184.5714 & 5.22357 & 179.7404 & 189.4024 & 179.00 & 194.00 \\
\hline FG & 7 & 201.4286 & 4.23703 & 197.5100 & 205.3472 & 196.00 & 209.00 \\
\hline G & 7 & 321.1429 & 3.53217 & 317.8761 & 324.4096 & 317.00 & 326.00 \\
\hline H & 7 & 308.0000 & 4.47214 & 303.8640 & 312.1360 & 300.00 & 313.00 \\
\hline HI & 7 & 287.2857 & 4.07080 & 283.5209 & 291.0506 & 281.00 & 292.00 \\
\hline I & 5 & 254.4000 & 3.36155 & 250.2261 & 258.5739 & 250.00 & 258.00 \\
\hline Total & 40 & 259.7250 & 53.61639 & 242.5776 & 276.8724 & 179.00 & 326.00 \\
\hline
\end{tabular}

Table II (one way ANOVA values) and Table III(Post-Hoc analysis) shows the difference between the groups and within the groups which is statistically significant.

IGF-1 levels at the peak pubertal growth were statistically higher than the start of pubertal growth, acceleration, deceleration, maturation of growth spurt and on completion of growth.

\section{Discussion :}

The factors that play a major role in treatment planning and retention in orthodontics are the timing of treatment and the amount of facial growth remaining. So it is very important to determine the biologic maturation level and growth potential

Table II

\begin{tabular}{|l|l|l|l|l|r|}
\hline \multicolumn{7}{|c|}{ ONEWAY ANOVA VALUE } \\
\hline & $\begin{array}{c}\text { Sum of } \\
\text { Squares }\end{array}$ & df & $\begin{array}{c}\text { Mean } \\
\text { Squares }\end{array}$ & F & $\begin{array}{c}\text { Signifi- } \\
\text { cance }\end{array}$ \\
\hline Between Groups & 111503.061 & 5 & 22300.612 & 1241.125 & .000 \\
\hline Within Groups & 610.914 & 34 & 17.968 & & \\
\hline Total & 112113.975 & 39 & & & \\
\hline
\end{tabular}




\section{Table III}

\section{Multiple Comparisons}

Dependent Variable: VALUE

Scheffe

\begin{tabular}{|c|c|c|c|c|c|c|}
\hline \multirow[t]{2}{*}{ (I) GROUPD } & \multirow[t]{2}{*}{ (J) GROUPD } & \multirow[t]{2}{*}{ Mean Difference (I-J) } & \multirow[t]{2}{*}{ Std. Error } & \multirow[t]{2}{*}{ Significance } & \multicolumn{2}{|c|}{ 95\% Confidence Interval } \\
\hline & & & & & Lower Bound & Upper Bound \\
\hline \multirow[t]{5}{*}{$\mathrm{F}$} & $\mathrm{FG}$ & $-16.8571(*)$ & 2.26577 & .000 & -24.8576 & -8.8567 \\
\hline & G & $-136.5714(*)$ & 2.26577 & .000 & -144.5719 & -128.5709 \\
\hline & $\mathrm{H}$ & $-123.4286(*)$ & 2.26577 & .000 & -131.4291 & -115.4281 \\
\hline & HI & $-102.7143(*)$ & 2.26577 & .000 & -110.7148 & -94.7138 \\
\hline & I & $-69.8286(*)$ & 2.48203 & .000 & -78.5927 & -61.0645 \\
\hline \multirow[t]{5}{*}{ FG } & $\mathrm{F}$ & $16.8571(*)$ & 2.26577 & .000 & 8.8567 & 24.8576 \\
\hline & $\mathrm{G}$ & $-119.7143(*)$ & 2.26577 & .000 & -127.7148 & -111.7138 \\
\hline & $\mathrm{H}$ & $-106.5714(*)$ & 2.26577 & .000 & -114.5719 & -98.5709 \\
\hline & $\mathrm{HI}$ & $-85.8571(*)$ & 2.26577 & .000 & -93.8576 & -77.8567 \\
\hline & $\mathrm{I}$ & $-52.9714(*)$ & 2.48203 & .000 & -61.7355 & -44.2073 \\
\hline \multirow[t]{5}{*}{ G } & $\mathrm{F}$ & $136.5714(*)$ & 2.26577 & .000 & 128.5709 & 144.5719 \\
\hline & FG & $119.7143(*)$ & 2.26577 & .000 & 111.7138 & 127.7148 \\
\hline & $\mathrm{H}$ & $13.1429\left(^{*}\right)$ & 2.26577 & .000 & 5.1424 & 21.1433 \\
\hline & $\mathrm{HI}$ & $33.8571(*)$ & 2.26577 & .000 & 25.8567 & 41.8576 \\
\hline & I & $66.7429(*)$ & 2.48203 & .000 & 57.9788 & 75.5070 \\
\hline \multirow[t]{5}{*}{$\mathrm{H}$} & $\mathrm{F}$ & $123.4286(*)$ & 2.26577 & .000 & 115.4281 & 131.4291 \\
\hline & $\mathrm{FG}$ & $106.5714(*)$ & 2.26577 & .000 & 98.5709 & 114.5719 \\
\hline & $\mathrm{G}$ & $-13.1429(*)$ & 2.26577 & .000 & -21.1433 & -5.1424 \\
\hline & $\mathrm{HI}$ & $20.7143(*)$ & 2.26577 & .000 & 12.7138 & 28.7148 \\
\hline & $\mathrm{I}$ & $53.6000(*)$ & 2.48203 & .000 & 44.8359 & 62.3641 \\
\hline \multirow[t]{5}{*}{$\mathrm{HI}$} & $\mathrm{F}$ & $102.7143(*)$ & 2.26577 & .000 & 94.7138 & 110.7148 \\
\hline & $\mathrm{FG}$ & $85.8571\left(^{*}\right)$ & 2.26577 & .000 & 77.8567 & 93.8576 \\
\hline & G & $-33.8571(*)$ & 2.26577 & .000 & -41.8576 & -25.8567 \\
\hline & $\mathrm{H}$ & $-20.7143(*)$ & 2.26577 & .000 & -28.7148 & -12.7138 \\
\hline & I & $32.8857\left(^{*}\right)$ & 2.48203 & .000 & 24.1216 & 41.6498 \\
\hline \multirow[t]{5}{*}{ I } & $\mathrm{F}$ & $69.8286\left(^{*}\right)$ & 2.48203 & .000 & 61.0645 & 78.5927 \\
\hline & FG & $52.9714\left(^{*}\right)$ & 2.48203 & .000 & 44.2073 & 61.7355 \\
\hline & $\mathrm{G}$ & $-66.7429(*)$ & 2.48203 & .000 & -75.5070 & -57.9788 \\
\hline & $\mathrm{H}$ & $-53.6000(*)$ & 2.48203 & .000 & -62.3641 & -44.8359 \\
\hline & $\mathrm{HI}$ & $-32.8857(*)$ & 2.48203 & .000 & -41.6498 & -24.1216 \\
\hline
\end{tabular}

during preadolescence and adolescence. Other factors like chronologic age, menarche, dental development, body weight, voice and breast changes are shown to be unreliable and impractical for estimation of pubertal growth spurt. Insulin-like growth factor I (IGF-I) is a polypeptide hormone 
synthesized mainly by the liver. It is a member of a group of hormones termed insulin-like growth factors which are considered as mediators for function of growth-hormone. It plays a major role in postnatal growth and precisely in the growth of longitudinal bone. ${ }^{4}$

IGF-1 levels are shown to be dependent on growth hormone before puberty. However, IGF-1 levels can also be independent of growth hormone during puberty as their production can be directly stimulated by androgens. Recent literature has shown the sensitivity of condylar cartilage to changes in IGF-1 concentrations. Therefore, Endocrinologists have been using IGF-1 levels to diagnose growth hormone disturbances. Chronologic age and sexual maturity stages have also been related to Serum IGF-1 levels showing their peak late in puberty. This peak is mainly due to the stimulation of growth hormone secretion by adrenal and gonadal steroids.

Remaining pubertal growth can be assessed throughout treatment using simple periapical $\mathrm{x}$ rays, obliterating the need for lateral cephalograms or hand-wrist X-rays. Periapical x-ray films can be a simple and accurate economic growth indicator for recording modified MP3 stages.

Advantages of the modified MP3 stages include:

1. Significant lower radiation exposure.

2. High degree of clarity, with no variations in posture or superimposition of bones.

3. Easily identifiable, discrete stages of development.

4. Close correlation to CVMI stages.

5. Standard dental $\mathrm{x}$-ray machine and periapical $\mathrm{x}$ ray film are enough. ${ }^{6}$

Taking into account the importance of IGF-1 as a growth hormone mediator and the easy accessibility and reliability of MP3 radiograph, the present study was done to assess the relationship between the both in predicting skeletal maturity.

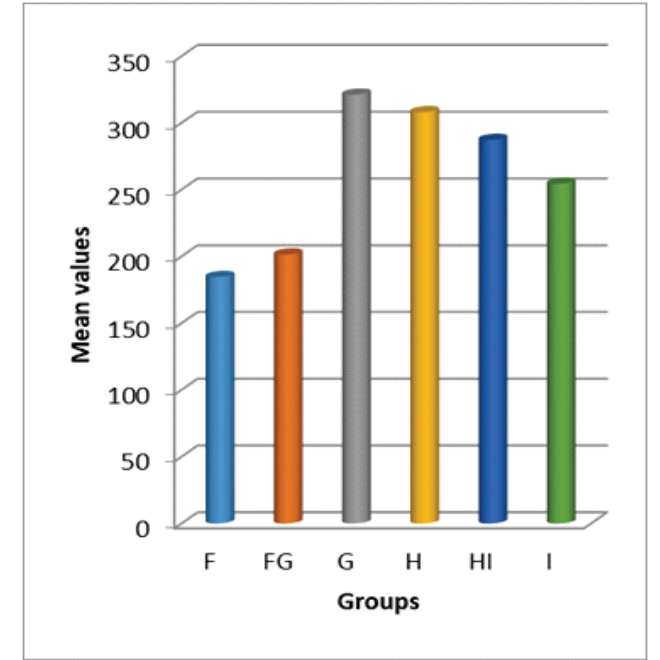

Graph showing the mean values of IGF-1 in each MP3 stage.

\section{Interpretation of the result}

The data in this study shows that IGF-I levels are low at the prepubertal stages of MP3 development. There was a sharp increase in IGF-I levels from FG to peak levels at $\mathrm{H}$, whereas there was a decline between $\mathrm{H}$ and I. Mean IGF-I levels at $\mathrm{G}$ and $\mathrm{H}$ were significantly higher than at the other stages.

This is consistent with previous studies that showed that IGF-I levels peak in late puberty. The descriptive statistical analysis shows mean value of IGF-1 at F stage is $184.57 \mathrm{ng} / \mathrm{ml}$ which peaked at $\mathrm{G}$ and $\mathrm{H}$ stages with $321.14 \mathrm{ng} / \mathrm{ml}$ and $308 \mathrm{ng} / \mathrm{dl}$ respectively which shows a decline towards completion of growth with I stage showing 254ng/dl ( Table 1 ).

1-Way ANOVA analysis and Post Hoc analysis shows that there is a statistically significant difference between the groups with $\mathrm{P}<0.001$ ( Table II \& III).

This graph shows that IGF-1 levels were higher at $\mathrm{G}$ and $\mathrm{H}$ stages when compared to the other stages. This demonstrates that increased IGF-1 levels were seen at pubertal and post pubertal stages of growth.

\section{It was inferred from the study that}

1. IGF-I levels are low at the prepubertal stages of 


\section{MP3 development.}

2. There was a sharp increase in IGF-I levels from FG to peak levels at $\mathrm{H}$.

3. There was a decline in IGF-1levels between $\mathrm{H}$ and I.

4. Mean IGF-I levels at $\mathrm{G}$ and $\mathrm{H}$ were significantly higher than at the other stages.

5. This is consistent with previous studies which showed that IGF-I levels peak in late puberty.

\section{Clinical implications}

The driving force in the quest for the most accurate and least invasive methodology to track pubertal growth spurt is the importance of growth determination. Other factors like chronologic age, menarche, dental development, body weight, voice and breast changes are shown to be unreliable and impractical for estimation of pubertal growth spurt. Skeletal growth changes during puberty are correlated with skeletal age assessments using hand-wrist and lateral cephalometric radiographs. The most reliable skeletal maturation indicator is the hand-wrist maturation indicator. However an alternative method to detect pubertal growth-spurt timing are IGF-I blood levels. It was concluded that the mandibular growth velocity pattern proposed by Fishman et al mirrored mean IGF-I levels at various skeletal stages.

The major disadvantage of hand-wrist radiographs and cervical vertebral staging is that the final stage does not necessarily indicate the completion of growth along with radiation exposure and staging of the $\mathrm{x}$-rays. The results of this particular study showed that IGF-I is a good indicator for predicting skeletal maturity.

\section{References:}

1. Fishman LS. Radiographic evaluation of skeletal maturation. A clinically oriented method based on Hand-Wrist films. The Angle Orthodontics 1982.
2. Brent Hasssel, Allan G Farman. Skeletal maturation evaluation using cervical vertebrae. Am J Orthod Dentofac Orthop 1995.

3. Masoud M, Masoud I, Kent LR Jr, Gowharji N, Cohene EL. Assessing skeletal maturity by using blood spot insulin-like growth factor (IGF-I) testing. Am J Orthod Dentofacial Orthop 2008.

4. Ishaq RAR, Soliman SAZ, Foda MY, Fayed MMS. Insulin like growth factor1: A biologic maturation indicator. Am J Orthod Dentofacial Orthop 2012.

5. Masoud MI, Masoud I, Kent LR Jr, Gowharji N, Hassan AH, Cohen LE. Relationship between blood-spot insulin-like growth factor 1 levels and hand-wrist assessment of skeletal maturity. Am J Orthod Dentofacial Orthop 2009.

6. Rajagopal R, Kansal S. A comparison of modified MP3 stages and the cervical vertebrae as growth indicators. JCO2002

7. Hagg U. Taranger J. Skeletal stages of the hand and wrist as indicators of the pubertal growth spurt. Acta Odontol Scand 1980; 32 (3):187 2008.

8. Nadler GL. Earlier dental maturation: Fact or Fiction?. The Angle Orthodontist 1998; 68(6):535-538

9. Rajagopal R, Kansal S. A comparison of modified MP3 stages and the cervical vertebrae as growth indicators. JCO2002; 36(7):398-406

10. Garcia - Fernandz P, Torre H, Flores L, Rea J. The cervical vertebrae as maturational indicators. JCO 2003; 35(4):221-225

11. Ozer T, Kama JD, Ozer SY. A practical method for determining pubertal growth spurt. Am J Orthod Dentofacial Orthop 2006; 103:131136.

12. Kamala M,Ragini, Goyal S. Comparative evaluation of hand wrist radiographs with cervical vertebrae for skeletal maturation in 10 - 12 years pld children. J Indian Soc Pedod Prev Dent 2006; Sep: 127-135. 